\begin{tabular}{ll}
\hline ノート Notes \\
\hline
\end{tabular}

\title{
液体シンチレータ廃液の前処理に関する基礎的研究1)
}

\author{
佐々木 徹, 小島周二 \\ 帝京大学薬学部
}

\section{A Fundamental Study on the Pretreatment of Liquid Scintillation Waste}

\author{
Toru SASAKi and Shuji KoJIMA \\ Faculty of Pharmaceutical Sciences, Teikyo University, \\ 1091-1, Suarashi, Sagamiko-machi, Tsukui-gun, Kanagawa
}

(Received January 18, 1982)

\begin{abstract}
Pretreatment of liquid scintillation wastes containing hydrophilic radioactive compounds before combustion was studied.

In various kinds of scintillation solutions, high removal percentages of the radioactivity were observed with calcium hydroxide $\left(\mathrm{Ca}(\mathrm{OH})_{2}\right)$, molecular sieves, and synthetic zeolite compared with anhydrous calcium chloride $\left(\mathrm{CaCl}_{2}\right)$, aluminum oxide, and silicic acid. The retention capacities of $\mathrm{CaCl}_{2}$ and $\mathrm{Ca}(\mathrm{OH})_{2}$ for ${ }^{14} \mathrm{C}$-methanol were approximately twice those of molecular sieves and synthetic zeolite. One gram of $\mathrm{Ca}(\mathrm{OH})_{2}$ was effective in the removal of radioactivity from $10 \mathrm{ml}$ of toluene-triton scintillator waste if it contained less than $10 \%(\mathrm{v} / \mathrm{v})$ of water. In case of waste which contains only a trace amount of hydrophilic labeled compounds, it is possible to remove the radioactivity by the treatment with $\mathrm{CaCl}_{2}$ or $\mathrm{Ca}(\mathrm{OH})_{2}$. Treatments with molecular sieves with suitable micropore size or synthetic zeolite were effective to remove the radioactivity from the waste containing hydrophilic substances.

These data indicate that, by the combination of these pretreatments, it is possible to remove the radioactivity from the various wastes.
\end{abstract}

Keywords - liquid scintillation waste; removal; radioactivity; anhydrous calcium chloride; calcium hydroxide; molecular sieves; synthetic zeolite

\section{緒言}

昭和55年9月に Isotope news 誌に揭載された放射性 有機廃液焼却に関する安全指針 22 に上れば，液体シンチ レータ廃液 (以下液シン廃液) を焼却する場合, 液シン 廃液中の放射性同位元素濃度 (以下 RI 濃度) を測定し, その值が $1 \times 10^{-3} \mu \mathrm{Ci} / \mathrm{cm}^{3}$ 以下であることを確認するこ と，また RI 濃度が高いものは希积して燒却するのでは なく RI の分離等必要な前処理を行うこととしている. 現在, 液シン廃液の前処理法としては蒸留法 ${ }^{-5)}$ が一般 的になりつつあるが，一部廃液（長期保管によって ${ }^{3} \mathrm{H}$ が水等と交換反応を起こしている場合, シンチレータの 主な成分であるトルェン，キシンン等と近い沙点を有す
る標識化合物, 例えばアルコール等を含む液シン廃液） では蒸留法による前処理が無効である。

先の報告6) では，無水塩化カルシウム $\left(\right.$ 以下 $\left.\mathrm{CaCl}_{2}\right)$ の 脱水作用似着目し，蒸留法では処理することが無効であ った ${ }^{3} \mathrm{H}$ 標識化合物走含む長期保管液シン廃液から RI を除去することを試みた。本研究は， $\mathrm{CaCl}_{2}$ (吸收剬) 抢上び種々の吸着剤（以下，吸収之吸着を総称して収着 と略す）を用い，親水性液シン廃液からの RI 除去率を 比較した.

\section{実 験 方 法}

1. 収着処理 調製液シン廃液 $(20 \mathrm{ml})$ を $50 \mathrm{ml}$ 三 角フラスコにとり，収着剂それぞれ $2 \mathrm{~g}$ 添加し室温で 30 
分間振とう後, Toyo 沪紙 No. $5(9 \mathrm{~cm})$ にて沪過し, 沪液を処理液とした。処理前後の RI 濃度は液体シンチ レーションカウンタ (Aloka LSC 903) にて測定し, 除 去率を求めた。

2. 収着剤 塩化カルシウム $\left(\mathrm{CaCl}_{2}\right)$ : 水分測定 用, 水酸化カルンウム $\left(\mathrm{Ca}(\mathrm{OH})_{2}\right)$ : 化学用, 酸化アル ミナ $\left(\mathrm{Al}_{2} \mathrm{O}_{3}\right)$ : 試薬特級,ケイ酸 $\left(\mathrm{SiO}_{2} \cdot \mathrm{H}_{2} \mathrm{O}\right)$ : 試薬特 級，モレキュラシーブス: A4，1/16, 合成ゼオライト：

A4, Powder 200 mesh.

以上和光純薬製を使用した。

\section{3. 調製液シン廃液 標識化合物一以下の標識化} 合物をシンチレータ 11 に対し添加した。

(a) ${ }^{14} \mathrm{C}-$ メ タノ $-ル 100 \mathrm{mmol}(4 \mu \mathrm{Ci})$

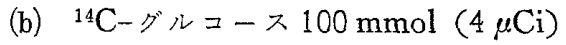

(c) ${ }^{3} \mathrm{H}-$ グリセロール $100 \mathrm{mmol}(1.6 \mu \mathrm{Ci})$

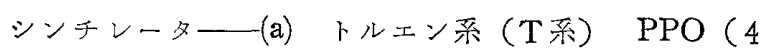

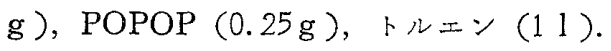

(b) トルェン一メタノール系 (TM 系) PPO (4g), $\operatorname{POPOP}(0.25 \mathrm{~g}), \quad ト ル ェ ン(0.91)$, メタノール (0.11).

(c) ジ丶キサン系( D系) PPO (4g), POPOP (0.05 $\mathrm{g})$, ナフタレン $(120 \mathrm{~g})$ にジオキサンを加え全量 11 とした.

(d) トルェンートライトン系(TT系) $\mathrm{PPO}(5.5 \mathrm{~g})$, $\operatorname{POPOP}(0.1 \mathrm{~g})$, トルェン $(0.6771)$, トライトンX$100(0.3331)$.

(e) バイオフロール (B系) NEN 社製, 組成不明.

4. 保持容量の比較 トルェン溶液に ${ }^{14} \mathrm{C}-メ タ$ 一
ール $(0.08 \mu \mathrm{Ci} / \mathrm{ml})$ 溶液をモル牙率 $(0.05-0.60) に$ なるよらに添加し、調製したトルエンー ${ }^{14} \mathrm{C}$ なタノール 混合溶液それぞれ $20 \mathrm{ml}$ は，1 g の収着剤を添加し，以

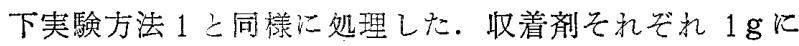
濃縮した ${ }^{14} \mathrm{C}$ 一メタノールの収着量（モル）は，処理前後 の RI 濃度と溶液量の差から求めた。

\section{5. 親水性溶媒の影響 ${ }^{14} \mathrm{C}$-メタノール $(0.08 \mu \mathrm{Ci})$}

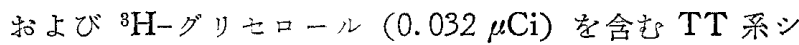
ンチレータ $20 \mathrm{ml}$ に $1.2 \times 10^{-3}-10^{-1}$ モルのベンゼン, アセトン, ジ方市ン，メタノールを等モルずつ加壳, それぞれ収着剤 $2 \mathrm{~g}$ にて実験方法 1 と同樣に処理し除去 率を比較した。

6. 含水率の影響 ${ }^{14} \mathrm{C}-$ グルコース $(0.04 \mu \mathrm{Ci})$ を 含屯 TT系シンチレータ $10 \mathrm{ml} K, 30 \%(\mathrm{v} / \mathrm{v})$ まで水 を添加し，そ礼资れ收着剂 $1 \mathrm{~g}$ 亿て実験方法 1 と同様に 処理し除去率を此較した。

\section{結果と考察}

\section{1. $\mathrm{CaCl}_{2}$ による液シン廃液処理}

Table I にシンチレータ別の RI 除去率を示した。そ

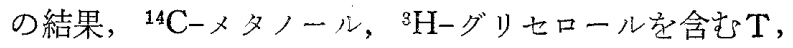
TM 系シンチレータからの RI 除去率は 95.2\%，99.4\% を示した・親水性シンシンータであるD，B系からの除 去率は60-70\%程度で㒸った。 さらに, 親水性ンンチレ ータである TT 系シンチレータでは $\mathrm{CaCl}_{2}$ の結晶が溶 解したため収着処理できなかった。

\section{2. 種々の親水性収着剂による RI 廃液処理}

$\mathrm{CaCl}_{2}$ についてンンチンータ別に RI 除去率壱比較し た結果，親油性に比して親水性シンチレータで除去率の

TABLE I. Removal of Radioactivity from the Liquid Sintillation Waste by $\mathrm{CaCl}_{2}$

\begin{tabular}{|c|c|c|c|c|}
\hline $\begin{array}{l}\text { Labeled } \\
\text { compounds }\end{array}$ & Scintillator & $\begin{array}{c}\text { Before treatment } \\
(\mathrm{dpm} / \mathrm{ml} \text { of the waste })\end{array}$ & $\begin{array}{l}\text { After treatment } \\
(\mathrm{dpm} / \mathrm{ml} \text { of the waste })\end{array}$ & $\begin{array}{c}\text { Removal } \\
\text { percentage }(\%)\end{array}$ \\
\hline \multirow[t]{4}{*}{${ }^{14} \mathrm{C}-$ Methanol } & $\mathrm{T}$ & 8800 & 420 & 95.2 \\
\hline & $\mathrm{D}$ & 8800 & 4043 & 54.1 \\
\hline & $\mathrm{TT}$ & 8800 & 7930 & 9.9 \\
\hline & $\mathrm{B}$ & 8800 & 1097 & 87.5 \\
\hline \multirow[t]{3}{*}{${ }^{14} \mathrm{C}-\mathrm{Glucose}$} & $\mathrm{D}$ & 7100 & 3233 & 54.5 \\
\hline & $\mathrm{TT}$ & 7100 & 7011 & 1.3 \\
\hline & $\mathrm{B}$ & 7100 & 1889 & 73.4 \\
\hline \multirow[t]{3}{*}{${ }^{3} \mathrm{H}-\mathrm{Glycerol}$} & $\mathrm{TM}$ & 3500 & 20 & 99.4 \\
\hline & $\mathrm{D}$ & 3500 & 1350 & 61.4 \\
\hline & $\mathrm{TT}$ & 3500 & 3426 & 2.1 \\
\hline
\end{tabular}

T: Toluene scintillator, D: Dioxane scintillator, TT: Toluene-Triton scintillator, B: Biofluor scintillator, TM: Toluene-Methanol scintillator.

Removal percentages were calculated as :

removal percentage $=\frac{\text { before treatment }(\mathrm{dpm} / \mathrm{ml} \text { of the waste })-\text { after treatment }(\mathrm{dpm} / \mathrm{ml} \text { of the waste })}{\text { before treatment }(\mathrm{dpm} / \mathrm{ml} \text { of the waste })} \times 100(\%)$. 
T $\mathrm{ABLE}$ II. Removal of Radioactivity from the Liquid Scintillation Waste by Various Absorbents

\begin{tabular}{|c|c|c|c|c|c|c|}
\hline \multirow{2}{*}{$\begin{array}{l}\text { Labeled } \\
\text { compounds }\end{array}$} & \multirow{2}{*}{ Scintillator } & \multicolumn{5}{|c|}{ Removal percentage $(\%)$} \\
\hline & & $\mathrm{Ca}\left(\mathrm{OH}_{2}\right)$ & $\mathrm{Al}_{2} \mathrm{O}_{3}$ & $\mathrm{SiO}_{2} \cdot \mathrm{H}_{2} \mathrm{O}$ & $\begin{array}{l}\text { Molecullar } \\
\text { sieves }\end{array}$ & $\begin{array}{l}\text { Zeolite } \\
\text { synthetic }\end{array}$ \\
\hline \multirow[t]{4}{*}{${ }^{14} \mathrm{C}-$ Methanol } & $\mathrm{T}$ & 97.6 & 97.5 & 97.0 & 99.4 & 96.6 \\
\hline & $\mathrm{D}$ & 90.1 & 26.6 & 25.5 & 88.4 & 96.3 \\
\hline & $\mathrm{TT}$ & 81.3 & 74.1 & 81.6 & 88.2 & 97.5 \\
\hline & B & 96.3 & 86.3 & 93.5 & 92.1 & 90.0 \\
\hline \multirow[t]{3}{*}{${ }^{3} \mathrm{H}-$ Glucose } & $\mathrm{D}$ & 99.6 & 96.4 & 23.4 & 84.8 & 98.6 \\
\hline & $\mathrm{TT}$ & 99.0 & 96.3 & 95.1 & 96.2 & 99.5 \\
\hline & B & 83.1 & 86.3 & 80.3 & 91.7 & 96.1 \\
\hline
\end{tabular}

$\mathrm{T}:$ Toluene scintillator, D : Dioxane scintillator, TT $:$ Toluene-Triton scintillator, B : Biofluor scintillator. Removal percentages were calculated as :

removal percentage $=\frac{\text { before treatment }(\mathrm{dpm} / \mathrm{ml} \text { of the waste })-\text { after treatment }(\mathrm{dpm} / \mathrm{ml} \text { of the waste })}{\text { before treatment }(\mathrm{dpm} / \mathrm{ml} \text { of the waste })} \times 100(\%)$.

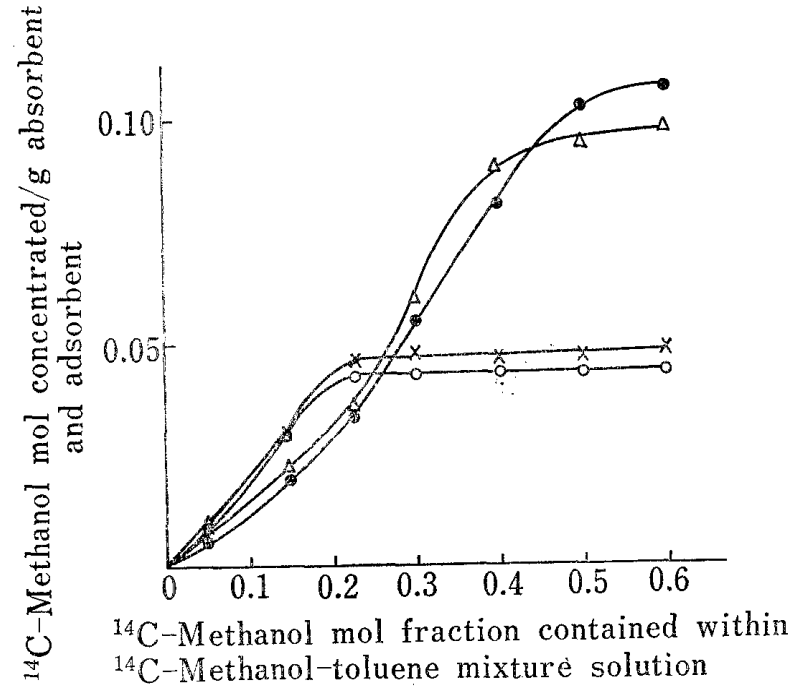

Fig. 1. Retention Capacities of $\mathrm{CaCl}_{2}, \mathrm{Ca}(\mathrm{OH})_{2}$, Molecular Sieves, and Synthetic Zeolite.

$\triangle, \mathrm{CaCl}_{2} ; \mathrm{Ca}(\mathrm{OH})_{2} ; \times$, molecular sieves; $\mathrm{O}$, synthetic zeolite.

低下する傾问が認められたことから， $\mathrm{CaCl}_{2}$ に代わる他 の親水性収着剂を検索し，その結果を Table II に示し た.

その結果, $\mathrm{CaCl}_{2}, \mathrm{Al}_{2} \mathrm{O}_{3}, \mathrm{SiO}_{2} \cdot \mathrm{H}_{2} \mathrm{O}$ 亿比して $\mathrm{Ca}(\mathrm{OH})_{2}$, モレキュラシーブス，合成ゼオライトがいずれのシンチ レータに执いても高除去率を示した。以下の実験では $\mathrm{CaCl}_{2}, \mathrm{Ca}(\mathrm{OH})_{2}$ ，モレキュラシーブス，合成ゼオライ トについて収着性能を比較した。

\section{3. 保持容量の比較}

トルェンーメタノール混合溶液中に和㐨る, $\mathrm{CaCl}_{2}$, $\mathrm{Ca}(\mathrm{OH})_{2}$ ，モレキュラシーブス，合成ゼオライトそれぞ れ $1 \mathrm{~g}$ の保持容量を ${ }^{14} \mathrm{C}$ 一メタノールを用いて比較した結

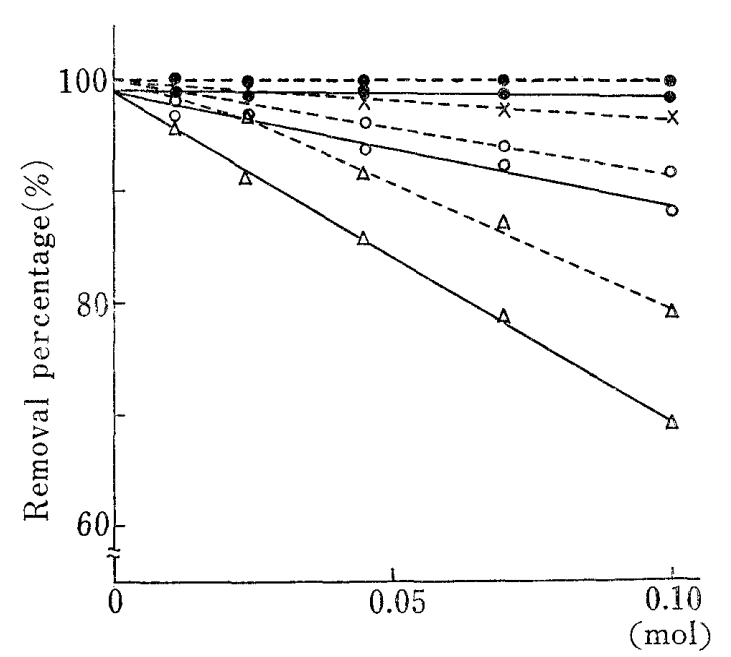

Hydrophilic solvents added to $20 \mathrm{ml}$ of the waste

Fig. 2. Effect of Benzene, Acetone, Dioxane, and Methanol on the Removal of Radioactivity by $\mathrm{CaCl}_{2}$ Treatment

- Benzene; $O$, acetone; $\triangle$, dioxane ; $x$, methanol. , ${ }^{14} \mathrm{C}$-methanol ; ......, ${ }^{3} \mathrm{H}$-glycerol.

Removal percentages were calculated as: removal percentage before treatment - after treatment $=(\mathrm{dpm} / \mathrm{ml}$ of the waste $)-(\mathrm{dpm} / \mathrm{ml}$ of the waste $)$ before treatment (dpm/ml of the waste) $\times 100(\%)$.

果，Fig. 1 亿示したよらにモレキュラシーブス，合成 ゼオライトは約0.05モルのメタノールを収着すると飽和 するのに対し, $\mathrm{CaCl}_{2}, \mathrm{Ca}(\mathrm{OH})_{2}$ には約 2 倍の保持容量 があることがわかった。

\section{4. 親水性溶媒の影響}

$\mathrm{RI}$ 除去率汇対する親水性溶媒の影響を ${ }^{14} \mathrm{C}$ 一メタノー

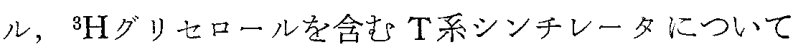




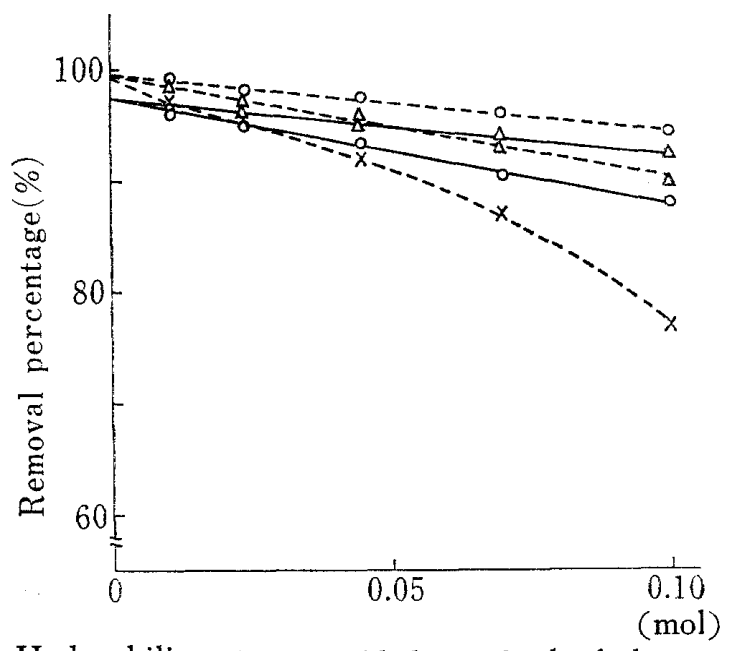

Hydrophilic solvents added to $20 \mathrm{ml}$ of the wasre

Fig. 3. Effect of Acetone, Dioxane, and Methanol on the Removal of Radioactivity by $\mathrm{Ca}(\mathrm{OH})_{2}$ Treatment

$O$. Acetone ; $\triangle$, dioxane ; $x$, methanol.

- ${ }^{14} \mathrm{C}$-methanol $; \cdots \cdots,{ }^{3} \mathrm{H}$-glycerol,

Removal percentages were calculated as :

removal percentage

$$
\text { before treatment _ after treatment }
$$

$=(\mathrm{dpm} / \mathrm{ml}$ of the waste $)-(\mathrm{dpm} / \mathrm{ml}$ of the waste $)$

before treatment $(\mathrm{dpm} / \mathrm{ml}$ of the waste)

$\times 100(\%)$

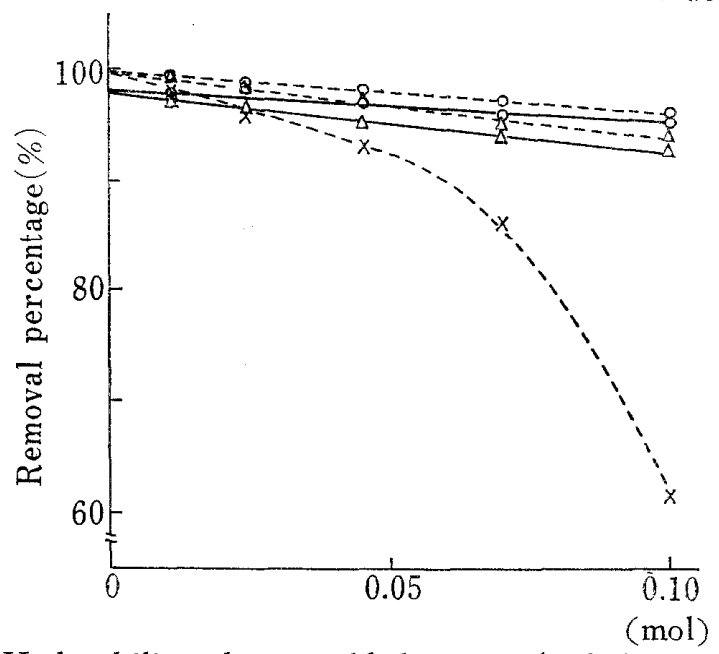

Hydrophilic solvents added to $20 \mathrm{ml}$ of the waste

Fig. 4. Effect of Acetone, Dioxane, and Methanol on the Removal of Radioactivity by Molecular Sieves Treatment

$O$. Acetone ; $\triangle$, dioxane ; $x$, methanol.

-, ${ }^{14} \mathrm{C}$-methanol ; ......, ${ }^{3} \mathrm{H}$-glycerol.

Removal percentages were calculated as :

removal percentage

$$
\text { before treatment _ after treatment }
$$

- (dpm/ml of the waste $)-(\mathrm{dpm} / \mathrm{ml}$ of the waste $)$

before treatment $(\mathrm{dpm} / \mathrm{ml}$ of the waste)

$\times 100(\%)$

比較検討した。 $\mathrm{CaCl}_{2}$ 処理に対する親水性溶媒の影警は

Fig. 2 に示したごとく, タノール，アセトン，ジオ キサンの順で除去率の低下が認められた，一方，㯒油性

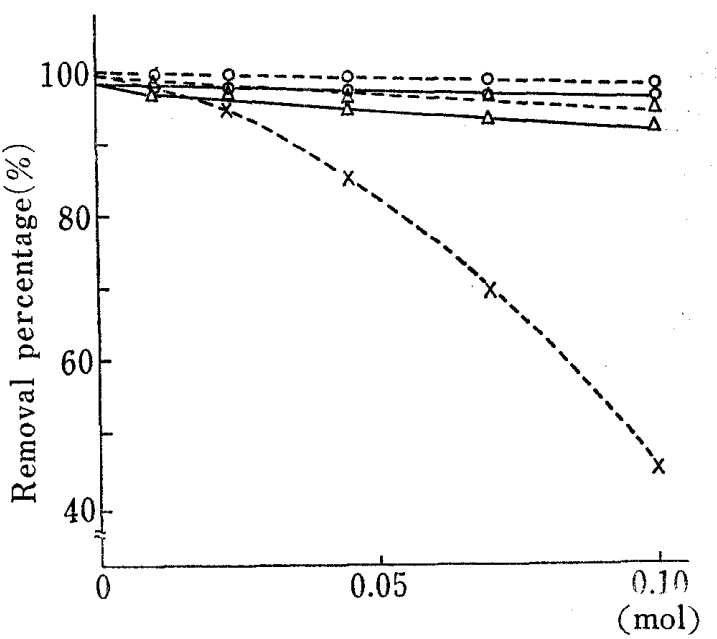

Hydrophilic solvents added to $20 \mathrm{ml}$ of the waste

Fig. 5. Effect of Acetone, Dioxane, and Methanol on the Removal of Radioactivity by Synthetic Zeolite Treatment

$O$. Acetone; $\triangle$, dioxane; $x$, methanol.

-, ${ }^{14} \mathrm{C}$-methanol ; ......, ${ }^{3} \mathrm{H}$-glycerol.

Removal percentages were calculated as :

removal percentage

before treatment - after treatment

$=(\mathrm{dpm} / \mathrm{ml}$ of the waste $)-(\mathrm{dpm} / \mathrm{ml}$ of the waste $)$ before treatment (dpm/ml of the waste) $\times 100(\%)$.

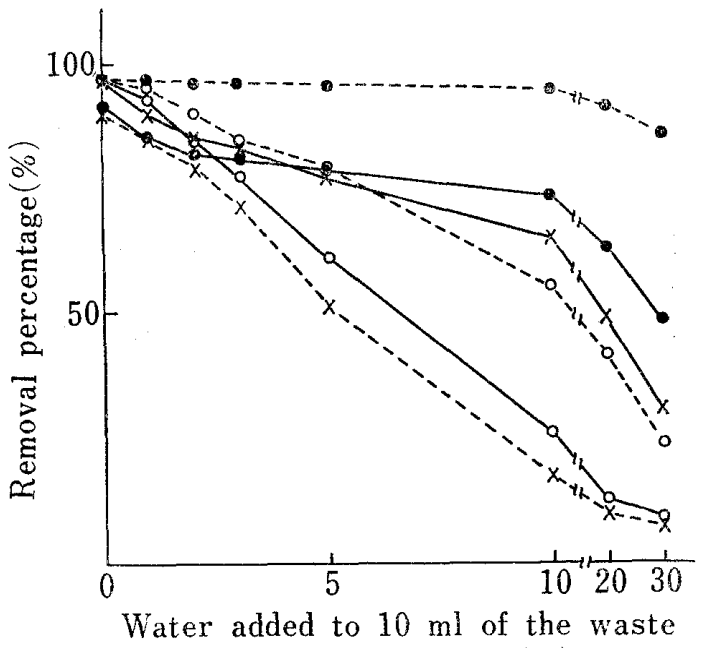

$(\%)$

Fig. 6. Effect of Addition of Water on the Removal of Radioactivity

- $\mathrm{Ca}(\mathrm{OH})_{2} ; \triangle$, moleculer sieves; $x$, synthetic zeolite. , ${ }^{14} \mathrm{C}$-methanol ; ......, ${ }^{3} \mathrm{H}$-glucose.

Removal percentages were calculated as : removal percentage

$=\left(\begin{array}{c}\text { before treatment } \\ \text { (dpm/ml of the waste })\end{array}-\begin{array}{c}\text { after treatment } \\ (\mathrm{dpm} / \mathrm{ml} \text { of the waste })\end{array}\right.$ before treatment $(\mathrm{dpm} / \mathrm{ml}$ of the waste) $\times 100(\%)$.

溶楪 (ベンゼン) の添加では，除去率の変化は認められ なかった. $\mathrm{Ca}(\mathrm{OH})_{2}$ の場合はアセトン，ジオキサン， メタノールの順に除去率の低下が認められた (Fig. 3). 
また，分子ふるい効果を有するモレキュラシーブス， 合成ゼオライトに対する影響をFig. 4，5亿示した。 そ の結果，いずれの収着剂に执いても分子径の大きいアセ トン, ジオキサンでは，ほとんど除去率の低下が認めら れないのに対し，分子径の小さいメタノール $(4 \AA)$ で は除去率の低下が顕著であった。

\section{5. 含水率の影響}

含水率の影響を通常 $20-30 \%(\mathrm{v} / \mathrm{v})$ 程度をで水を加 えることが可能である TT 系シンチレータについて収 着剂別比跤した (Fig. 6). その結果, $\mathrm{Ca}(\mathrm{OH})_{2}$ 処理

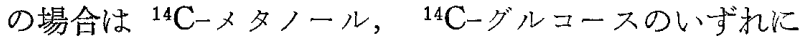
ついても含水率 $10 \%(\mathrm{v} / \mathrm{v})$ 程度玉でであれ机比較的高除 去率を保つことがわかった. 一方, 水の添加に伴うモレ キュラシーブス, 合成ゼオライトの除去率の低下は顕著 であった。これは，モレキュラシーブス，合成ゼオライ トの保持容量が $\mathrm{Ca}(\mathrm{OH})_{2}$ に比べて小さいこと, 使用し たモレキュラシーブス, 合成ゼオライトの細孔径 $4 \AA$ に 比べ, 水の分子径 $2.8 \AA$ が小さいためその影響を受けた ものと考完られる。

以上の結果から，トレーサ一量の親水性化合物を含む 液シン廃液を処理する場合には，モレキュラシーブス， 合成ゼオライトより大きい保持容量を持台，廉洒である
$\mathrm{CaCl}_{2}, \mathrm{Ca}(\mathrm{OH})_{2}$ が有利であると考台られる，さらに， 親水性物質を多量に含む廃液については，除去目的物質 上り分子径の大きい親水性物質であれば，適当な細孔径 を有するモレキュラシーブス，合成ゼオライトを用いる ことにより高除去率が得られる可能性が示唆された。モ レキュラシーブス，合成ゼオライトは，経済的理由から 再生使用する必要があると考えられる. 今後, 工業用モ レキラシーブス，合成ゼオライトを用いた実験を行い， その結果，高除去率が得られれば，再使用せずに $\mathrm{CaCl}_{2}$, $\mathrm{Ca}(\mathrm{OH})_{2}$ と同様にエポキシ樹脂等により固化し，固体 廃菓物として処理することる考えられる。

水分量の多い液シン廃液の前处理には，本法は不通で 西るが $10 \%(\mathrm{v} / \mathrm{v})$ 程度までの含水シンチりータであれば $\mathrm{Ca}(\mathrm{OH})_{2}$ を用いて处理すること加叮能であると考党ら れる. 本法は，今まで蒸留法では処理することが無効で あった長期保管廃液並びに標識アルコール廃液に対する 有效汉处理方法となるばかりでなく，トレーサー量の親 水性標識化合物を含さ液ンン廃液に対する簡便な処理方 法となることが期待できる、本法を実際の液シン廃液の 前処理に適用する場合, 液シン廃液の組成を明確にし， 細分類しなければならないこ秃は暁却に際する安全の 面からも必要なことである。

\section{引用文献および注}

1）日本薬学会第 101 年会で発表，熊本，1981年 4 月，

2) Isotope News, 315, 33 (1980).

3）金子孝夫，松尾光芳，Radioisotopes，28，91 (1979).

4) 馬場茂雄, 古田 隆, 五郎丸 毅, 堀江正信, Radioisotopes, 28, 775 (1979).

5）那波克己, 鬼沢隆彦, 高橋大器, 中里一久, 徳永 昇, 荒山 寛, Pure Chemical “Daiichi,” 9, 30 (1978).

6) 小島周二, 久保寺昭子, Radioisotopes, 28, 447 (1979). 